\title{
Transferência de Recursos através do Programa Bolsa Família no Município de Acauã-Piauí
}

\author{
Rogério Rodrigues de Macedo ${ }^{1}$
}

\begin{abstract}
Resumo: O presente trabalho tem como objeto de estudo, a transferência de renda às famílias beneficiadas pelo Programa Bolsa Família na cidade de Acauã do Piauí. O intuito geral do referido trabalho é analisar os impactos do PBF na trajetória escolar de famílias beneficiárias do programa no município de Acauã/PI, caracterizando o seu desenvolvimento frente à demanda atendida pelo programa. Como objetivos específicos da pesquisa têm-se: descrever as mudanças no acesso à educação nas vidas das famílias beneficiadas; verificar as condições de vida e de empregabilidade dos alunos beneficiários da primeira geração do PBF. A pesquisa teve que ser realizada em dois momentos e, por essa razão, trata-se de uma pesquisa de campo em que se faz a "observação dos fatos tal como ocorrem", e também será uma pesquisa de caráter bibliográfico, pois visa "recuperar o conhecimento acumulado de um problema" (SEVERINO, 2002, p.54).
\end{abstract}

Palavras Chave: Bolsa Família. Famílias. Benefício.

\section{Transfer of Resources through the Bolsa Família Program in the Municipality of Acauã in Piauí}

\begin{abstract}
The present study has as object of study, the transfer of income to families benefited by the Bolsa Família Program in the city of Acauã do Piauí. The general purpose of this study is to analyze the impacts of the PBF on the school trajectory of beneficiary families of the program in the municipality of Acauã / PI, characterizing its development against the demand of the program. Specific objectives of the research are: to describe the changes in access to education in the lives of beneficiary families; to verify the living conditions and employability of the beneficiary students of the first generation of the PBF. The research had to be carried out in two moments and, for this reason, it is a field research in which "facts are observed as they occur", and it will also be a bibliographical research, since it aims to "recover the accumulated knowledge of a problem "(SEVERINO, 2002, p.54).
\end{abstract}

Keywords: Bolsa Família. Families. Benefit.

\section{Introdução}

O Programa Bolsa Família (PBF) é um programa de transferência de renda com condicionalidades criadas pelo governo Lula no ano de 2003 para integrar e unificar ao Fome Zero três programas implantados no Governo Fernando Henrique Cardoso (FHC).

${ }^{1}$ Bacharel em administração Pública - UFPI. Contato: rogerio25121988@Gmail.com.br 
Um dos programas é o Bolsa Escola. Criado em 2001, tinha por objetivo combater a pobreza e oferecer as famílias cadastradas melhores condições de vida, por meio do acesso à educação. O Auxílio Gás era destinado as famílias de baixa renda, a cada dois meses. Era a forma encontrada pelo governo para o combate à falta de acesso aos alimentos das famílias carentes, com objetivo de sanar ou pelo menos tentar minimizar os problemas de desnutrição no país. E o Bolsa Alimentação objetivava proporcionar mais qualidade na alimentação de gestantes e mães lactantes, de 6 meses a 6 anos e 11 meses de idade. A principal crítica aos programas diz respeito ao alcance, volume de recursos investidos e falta de integração entre os programas, pois cada um era administrado por uma instância de governo diferente.

Bither-Terry (2012) defende que os baixos valores transferidos são insuficientes para provocar uma saída da pobreza, embora o Programa tenha conseguido reduzir a severidade da pobreza e possibilitado o acesso às necessidades básicas a muitas famílias.

Kerstenetzky (2009, p. 56-57), o benefício ajuda a diminuir a desigualdade de renda, mas não tem a mesma potência para enfrentar a pobreza devido ao baixo valor transferido.

A regulamentação do PBF foi feita através da Medida Provisória n 132 que em 2004 foi aprovada pelo Congresso Nacional e deu origem a lei $n^{\circ} 10.836$. Na introdução desse dispositivo legal está caracterizado a preocupação dessa política. Seu principal objetivo é combater a fome e incentivar a segurança alimentar e nutricional, promover o acesso das famílias carentes à rede de serviços públicos como educação e saúde, apoiar o desenvolvimento de famílias pobres e em situação de extrema pobreza, combate à pobreza e desigualdade e a união dos diversos órgãos públicos para auxiliar famílias pobres a superarem essa condição.

O Programa Bolsa Família (PBF) foi adotado como política pública do Governo Lula para proporcionar inclusão social e redistribuição de renda para as famílias brasileiras mais pobres. Esse programa é gerido pela Secretaria Nacional de Renda e Cidadania do MDS em parceria com estados e municípios.

Segundo dados do MDS, o PBF beneficia mais de 13,7 milhões de famílias em todo território nacional. No Piauí cerca de 450 mil famílias têm acesso ao programa. No município em questão, possui um total de 1366 beneficiários.

Muitos estudos têm se dedicado a analisar os resultados do PBF, principalmente por conta do seu impacto na diminuição da pobreza extrema. No que se refere a esse aspecto, Soares, Ribas e Osório (2010) constataram que o Bolsa Família contribuiu para a redução da 
desigualdade e da extrema pobreza no Brasil. Suas pesquisas revelam que o Programa teve uma participação de $21 \%$ na queda registrada no índice de Gini, sendo responsável pela diminuição de $12 \%$ na pobreza (hiato da pobreza) e de $19 \%$ na severidade da pobreza.

Outro aspecto bastante explorado diz respeito as condicionalidades do programa. Senna, Brandão e Dalt (2016) analisam que as condicionalidades têm suscitado um intenso debate na literatura especializada, dividindo opiniões entre analistas, gestores, profissionais, movimentos sociais e opinião pública. Os termos desse debate apontam, em linhas gerais, para questões como a (in) compatibilidade das condicionalidades com a lógica dos direitos de cidadania (Lavinas, 2013), argumentos éticos e políticos em torno de concepções sobre dever moral dos pobres (Medeiros, Britto e Soares, 2007) ou mesmo a pertinência e/ou adequação do tipo de condicionalidades aos objetivos enunciados pelo programa. $\mathrm{O}$ acompanhamento das condicionalidades reveste-se de grande complexidade, envolvendo diferentes setores governamentais e diversos atores sociais em sua implementação.

Segundo Weissheimer (2009) as condicionalidades do Bolsa Família referentes à frequência escolar e ao acompanhamento nutricional das crianças são alguns dos fatores que contribuíram para a melhoria desses indicadores.

Uma abordagem que tem sido pouco explorada é compreender o impacto educacional na história familiar. Um dos argumentos centrais do programa e que justificaria a reprodução intergeracional da pobreza está encadeada numa dinâmica em que a maior escolarização do beneficiário iria superar o nível educacional da família. Sendo assim, um dos aspectos que impede que o salário médio das famílias avance diz respeito ao grau de instrução. Se o filho não supera o grau de instrução dos pais, a tendência é ele reproduzir as condições de pobreza da família. Sem grau de instrução superior à família, o mercado de trabalho oferecerá as mesmas oportunidades que reproduzem as condições de vida da família.

Esse aspecto é tido por muitos autores como (KILL, 2014, p. 9-10) afirmando que o PBF foi criado "para garantir não apenas o direito de todas as crianças à Educação, mas sua permanência na escola para que tenham um futuro melhor, rompendo com o ciclo da pobreza que no passado, marcou gerações de famílias”.

Segundo Oliveira; Soares (2013, p. 21) "a frequência à escola, indica que alunos que cumprem a condicionalidade de frequência possuem chances menores de repetência do que aqueles que não cumprem", sendo fundamental para romper a reprodução intergeracional da pobreza. 
Importantes análises têm sido realizadas observando o impacto do PBF em municípios brasileiros. Martins (2011) analisou a pobreza e proteção social: um estudo sobre a permanência e a inclusão intergeracional das famílias inseridas no programa bolsa família (PBF) em Florianópolis.

Luís Carlos Santos Oliveira (2014) buscou observar o programa bolsa família: efeitos no desempenho escolar e na superação da vulnerabilidade social de beneficiários em Feira de Santana-BA (2006-2012).

Rosangela Santos e Santos e Simone Maria de Sousa Silva (2015), uma proposta: quebrar o ciclo de pobreza através da condicionalidade da educação do programa bolsa Família. Porém, o efeito das condicionalidades educacionais raramente é discutido.

Nessa premissa o trabalho busca o entendimento sobre as condicionalidades do programa Bolsa Família, se elevaram o grau de escolaridade das famílias oportunizando melhores condições de acesso ao mercado de trabalho na cidade de Acauã/PI.

Sendo assim, passados mais de 15 anos do início do programa é possível observar se os primeiros beneficiários conseguiram superar os níveis educacionais de sua família e verificar se isso garantiu entrada no mercado de trabalho em condições melhores que a família. Para tanto o estudo foi elaborado com base: (a) a escolaridade dos primeiros beneficiários do programa garantiu melhorar as condições de acesso ao mercado de trabalho comparado as duas gerações anteriores? (b) qual o impacto da condicionalidade educacional na mudança do perfil educacional da família?

\section{Os Programas Sociais Brasileiros}

\section{Parte I}

De acordo com Rosa Stein (2005) afirma que os Programas de Transferência de Renda, ou Programas de Renda Mínima têm sido pensados e implementados em diversos países tanto no continente europeu quanto na América Latina. Na Europa, os primeiros programas de transferência de renda começam a ser implementados da década de 1930, na América Latina no final dos anos 80 e início da década de 1990, quando os programas dos países europeus eram reformulados. 
Os programas de renda de transferências de renda no sistema brasileiro configuram-se como um sistema de proteção social que tem seus antecedentes históricos na década de 1930 que se caracterizou por ser um período de grandes transformações socioeconômicas em que se evidenciou a passagem do modelo de desenvolvimento agroexportador para o modelo urbanoindustrial (SILVA e SILVA, 2008).

De acordo com Silva e Silva (2008) esse período de mudanças econômicas também foi cenário para o reordenamento das funções do estado nacional, no momento em que este assume de forma extensiva a regulação ou provisão direta nos setores de saúde, educação, previdência e outras áreas sociais. Sendo assim, o sistema de proteção social avançou e se consolidou no período compreendido entre a década de 1970 a 1980 e isso acarretou aos programas sociais o funcionamento no modo de compensação a repressão e ao arbítrio somado à grande demanda imposta no período anterior. Ou seja, os programas sociais se aplicaram ou se expandiram como um tipo de compensação dirigido essencialmente aos movimentos sociais e sindicais.

Os grupos domésticos que possuem renda domiciliar per capita de até sessenta reais (em 2006) foram considerados em situação de extrema pobreza. A eles foi designado o benefício básico, de cinquenta reais. Foram considerados em situação de pobreza os grupos domésticos com renda domiciliar per capita de sessenta reais e um centavo a cento e vinte reais e que possuem domicílio gestantes, nutrizes, crianças entre 0 e 12 anos ou adolescentes até 15 anos; com limite de no máximo três beneficiários por domicílio (SANTOS, 2004).

Os primeiros programas deste gênero tiveram início em 1995, nas cidades de Campinas, São Paulo e Brasília, e desde então foram adotados em inúmeros outros lugares. De acordo com as estimativas de Cardoso e Souza, existiam 61 programas semelhantes em 1999, além dos 17 mantidos pela instituição não governamental Missão Criança (Cardoso e Souza, 2003).

De acordo com Cunha (2009) o PBF é caracterizado em três dimensões específicas: "alívio imediato da pobreza, por meio da transferência de renda direta, contribuição para a redução da pobreza intergeracional, por meio do cumprimento de condicionalidades e articulação com outras políticas públicas, de forma a desenvolver as capacidades das famílias beneficiárias".

Segundo o MDS “O desafio é articular os diversos agentes políticos em torno da promoção e inclusão social das famílias beneficiárias". Para isso, deve ser estabelecido um modelo de gestão compartilhada, com competências específicas para cada um dos entes federados. 
Durante o Governo Fernando Henrique Cardoso, finalmente os chamados programas de distribuição de renda foram efetivamente implantados no país, todos esses programas estavam agrupados na chamada rede de proteção social, de abrangência nacional (BRASIL, 2011). Foi a partir daí que realmente começa a andar os programas de transferência de renda, eles são implantados e as pessoas passam a ser beneficiadas.

Alguns autores realizaram vários estudos sobre os programas sociais no governo FHC. Draibe (2003) realiza uma análise sobre a política social no período FHC e o sistema de proteção social. Becker (2004) busca o entendimento sobre Políticas Sociais no Governo Fernando Henrique Cardoso. Rezende (2009) propõe um comparativo, uma análise das políticas macroeconômicas do governo FHC, governo LULA.

Na década de 90, desenvolveu-se uma mobilização social que reivindicava o "fim da fome no Brasil”. Neste período instaurou-se no Brasil um novo modelo de política social: a redistribuição de uma renda mínima às famílias - esta, definida a partir da convivência de seus membros em um mesmo domicílio, que estariam vivendo abaixo de um padrão socialmente aceitável.

\section{Parte II}

O Governo Federal (LULA), ao tomar a questão da fome símbolo da extrema desigualdade social e uma problemática do Estado, criou lateralmente ao Fome Zero o Programa de Transferência de Renda Mínima Bolsa Família (PBF). O intuito era redistribuir uma renda mínima base ao segmento social distinguido como potencial beneficiário mediante um déficit na renda domiciliar.

A criação do Bolsa família teve como inspiração o Bolsa Escola, programa criado na cidade de Campinas-SP em 1994 e logo em seguida no Distrito Federal em 1995, sendo implementado em 2001 pelo Governo Federal, é o mais importante das políticas sociais do governo brasileiro e é hoje o maior programa de transferência condicionada de capital do mundo (BRASIL, 2011).

O Programa Bolsa Família, que sancionado no governo do Presidente Luís Inácio Lula da Silva, pela Lei ${ }^{\circ} 10.836 / 04$, de acordo com o ministério do Desenvolvimento Social, o benefício tem como objetivo atender as famílias em estado de vulnerabilidade e extrema 
pobreza, vivendo com o limite de $\mathrm{R} \$ 70,00$ (setenta reais) onde para essas famílias é atribuir dá uma renda básica de $\mathrm{R} \$ 70,00$ no qual elas poderão ser acrescidas de $\mathrm{R} \$ 38,00$ (trinta e oito), este é o benefício básico, podendo ser variável e vinculado ao adolescente, conhecido por benefício variável jovem (BVJ).

O programa segue algumas etapas: (a) identificação do público que será acompanhado; (b) envio do público para acompanhamento aos parceiros das áreas de educação e saúde; (c) períodos de acompanhamento das condicionalidades do PBF e de registro das informações nos sistemas; (d) consolidação dos resultados do acompanhamento; (e) aplicação dos efeitos sobre os benefícios, aviso às famílias e apresentação de recursos; (f) análise e sistematização de informações para subsidiar outras políticas; (g) trabalho social com famílias. A gestão das condicionalidades do Programa Bolsa Família é um trabalho de parcerias entre os três níveis de governo (federal, estadual e municipal), e entre vários setores, sendo que essas contingências são compromissos assumidos entre o poder público e as famílias beneficiárias nas áreas de Saúde e Educação.

O programa é o maior existente no contexto de transferência de renda no país, sendo este, a unificação de outros programas, que tem como objetivo de amenizar as desigualdades sociais e reduzir a pobreza. Segundo Dias e Carvalho, em sua tese, afirma que o maior programa de transferência condicionada de capital do mundo. O Programa Bolsa Família consistiu na unificação e ampliação desses programas sociais, um único programa social, com cadastro e administração centralizados no Ministério do Desenvolvimento Social e Combate à Fome o que, segundo o Banco Mundial (sitio educacao.mg.gov.br), facilita sua eficiência administrativa e fiscalização.

O propósito da unificação, para o Governo Federal, era ter uma ampla visão do composto das famílias beneficiárias de renda mínima; do acompanhamento desta em relação às contrapartidas; e dos recursos direcionados à política social.

Segundo a Organização das Nações Unidas para Agricultura e Alimentação (FAO) uma pessoa pobre é aquela que não tem dinheiro para garantir uma refeição que forneça 1750 calorias por dia. A pobreza é um fator recorrente que está inserida na sociedade, abrangendo uma série de fatores, vinculados a economia até mesmo a cultural.

Para Malthus, a maior parte dos problemas da pobreza é culpa dos próprios pobres, que não têm determinação e força de vontade para trabalhar [...] a causa principal da pobreza era a grande velocidade com que as pessoas se multiplicavam, em contraste com a pouca velocidade 
em que crescia a produção de alimentos. O problema se resolveria facilmente se os pobres controlassem seus impulsos sexuais e deixassem de ter tantos filhos. (SCHWARTZMAN, 2004, p.).

Tratando da pobreza no Brasil, observa uma disparidade entre regiões, onde os Estados do norte e nordeste têm os maiores índices de pobreza do País. Essas disparidades ocorrem por meio da concentração política e industrial estabelecida no sul do País devido ao processo de colonização.

O Ministério do Desenvolvimento Social definiu que a linha de pobreza no Brasil é quem vive com uma renda de até 140 reais por mês. Mais de 28 milhões de brasileiros estão nessa condição. São vários os motivos que podem levar ao crescimento e agravamento da pobreza em determinada região, tais como: econômicos, socioculturais, históricos, naturais e político-legais.

Desigualdade social é contextualizada como diferenças econômicas que existem em diversos grupos de indivíduos no meio social. Nessa perspectiva, essas desigualdades ocasionam problemas para a sociedade, onde as diferenças de rendas são alarmantes originando as disparidades econômicas.

$\mathrm{Na}$ atual sociedade as desigualdades sociais sempre existiram, pois é impossível que cada indivíduo adquiram os mesmos valores financeiros. As principais causas dessas desigualdades são: má distribuição de renda, má administração dos recursos, lógica de acumulação do mercado capitalista (consumo, mais-valia), falta de investimento nas áreas sociais, culturais, saúde e educação, falta de oportunidades de trabalho e a corrupção.

Segundo Camargo (2018), a desigualdade social é um guarda-chuva que compreende diversos tipos de desigualdades, desde desigualdade de oportunidade, resultado, etc., até desigualdade de escolaridade, de renda, de gênero, etc. De modo geral, a desigualdade econômica - a mais conhecida - é chamada imprecisamente de desigualdade social, dada pela distribuição desigual de renda. No Brasil, a desigualdade social tem sido um cartão de visita para o mundo, pois é um dos países mais desiguais. Segundo dados da ONU, em 2005 o Brasil era a $8^{\circ}$ nação mais desigual do mundo. O índice Gini, que mede a desigualdade de renda, divulgou em 2009 que a do Brasil caiu de 0,58 para 0,52 (quanto mais próximo de 1, maior a desigualdade).

$\mathrm{O}$ PBF na sua atualidade, consiste em um programa para agregar valores no combate às desigualdades e a pobreza. Esse programa contém um número de beneficiários expressivo 
quando comparável ao das grandes políticas sociais, como a saúde e educação públicas e a previdência social, criando uma espinha dorsal da política social brasileira.

O PBF cumpre um importante papel em sua primeira fase, os impactos do programa na redução da pobreza, diminuir as desigualdades, criando meios que seus beneficiários permaneçam na escola diminuindo o trabalho infantil. Nesse sentido, torna-se fundamental o investimento no PBF para suprir os desafios das necessidades de programas de assistência social no Brasil.

Soares e Sátyro (2009) aborda o desenho institucional e a implementação do PBF e conclui que o programa não é nem totalmente um programa de geração de oportunidades nem plenamente um programa de proteção social. Ainda assim a avaliação dos autores é bastante positiva: o PBF é uma política revolucionária em termos de política social no Brasil. Embora produto de uma trajetória prévia nas políticas sociais, o PBF revolucionou a proteção social no país. Os impactos do PBF foram relevantes no combate à desigualdade e a algumas medidas de pobreza, e dele não decorrem impactos negativos.

No que tange às condicionalidades educacionais, as famílias beneficiárias do PBF deverá realizar matrículas das crianças e adolescentes de 6 a 17 anos na escola: a) para as crianças ou adolescentes de 6 (seis) a 15 (quinze) anos de idade, a matrícula e a frequência mínima de $85 \%$ (oitenta e cinco por cento) da carga horária escolar mensal; e b) para os adolescentes de 16 (dezesseis) e 17 (dezessete) anos de idade, cujas famílias recebam o Benefício Variável Vinculado ao Adolescente - BVJ, a matrícula e a frequência mínima de $75 \%$ (setenta e cinco por cento) da carga horária escolar mensal; c) também a obrigatoriedade de informar ao gestor do Programa Bolsa Família qualquer mudança de escola.

O PBF quando adequando com o monitoramento das condicionalidades possibilita a visualização de vulnerabilidades que causará o afastamento ou impedimento das famílias beneficiárias aos serviços do programa.

De acordo com Santos e Silva (2015) "exigência na gestão das condicionalidades na área de educação, no que se refere à frequência escolar mínima para crianças e adolescentes de famílias atendidas pelo Programa Bolsa Família, foi estabelecida com o objetivo de romper o chamado ciclo intergeracional da pobreza. Neste sentido, o incremento da frequência escolar de crianças e adolescentes de famílias pobres e extremamente pobres pode promover melhores condições para que essas estes ingressem futuramente no mercado de trabalho quando na idade adulta, o que também poderá acarretar no aumento da renda familiar e, consequentemente, 
promover a saída da condição de pobreza em relação à geração de seus pais, tudo isso se dá no enfrentamento de mecanismos de reprodução da pobreza".

Osório (2010), atesta que o Bolsa Família teve nacionalmente um impacto significativo sobre a frequência escolar. Convém conhecer a percepção das beneficiárias locais sobre a frequência após a concessão do benefício.

Alguns estudos apontaram que o cumprimento às condicionalidades não estaria sendo satisfatoriamente fiscalizado pelo governo. Estudos como: “As condicionalidades do Programa Bolsa Familia sob a ótica dos gestores: entre a expectativa e a realidade”, publicado no site: www.uel.br, por Cássia Maria Carloto, Tatiana de Oliveira Stechi e Bárbara Weinert Ferreira Nogueira, pesquisa apontou fragilidade no que diz respeito ao monitoramento e avaliação dentro do programa no âmbito dos municípios.

Segundo dados do Ministério da Saúde, em 2006 não foram monitorados, por falta de dados, a condicionalidade exigida em relação a $68 \%$ das famílias beneficiadas, tais falhas fizeram com que, por exemplo, os índices de vacinação e de nutrição entre famílias beneficiadas e não beneficiadas fossem equivalentes, essas falhas apontadas já vêm sendo corrigidas.

O Ministério da Educação recebeu 78,9\% das informações relativas à participação escolar das crianças e adolescentes cadastrados no Programa, o que representou uma melhoria de 10 pontos percentuais em relação a maio e abril do mesmo ano, com isso, dos mais 15 milhões de alunos atendidos, 11 milhões tiveram a participação escolar computada (BRASIL, 2011).

O Programa Bolsa Família concede benefícios para a família em situação de extrema pobreza que tenham crianças até 15 anos de idade, com condição de que as crianças estejam matriculadas na escola. Estudos desenvolvidos, como: "Bolsa Família: 11 anos e 11 conquistas, publicado na revista eletrônica Carta Capital, por Rosana Pinheiro Machado e Luana Goveia - publicado 24/10/2014”, têm mostrado que programas de transferência condicionada a renda, aumenta o número de criança matriculadas, reduzem o trabalho infantil, melhorando o estado nutricional e de saúde das crianças e até diminuem a desigualdade de renda (BRASIL, 2011).

Nos últimos 25 anos, os países latino-americanos realizaram progressos significativos em relação ao aumento do número de matriculas e a melhoria do desempenho escolar dos alunos. No entanto, ainda há espaço para novos avanços, embora para a faixa etária de 8 a 11 anos a taxa de matriculas no Brasil tenha aumentado de 86\% em 1990, para 97\% em 2011 para 
a faixa etária de 14 anos a taxa era de $92 \%$ em na de 15 anos apenas 87\%. Ademais, $40 \%$ (nove milhões) dos jovens brasileiros, entre 18 e 25 anos, não tinham 8 anos de escolaridade completos (PNAD, 2011)

Ao entrar no programa Bolsa Família, a Família se compromete a cumprir as condicionalidades do Programa nas áreas de saúde, educação que são manter as crianças e adolescentes em idade escolar frequentando a escola e cumprir os cuidados básicos em saúde (BRASIL, 2011).

Partimos do pressuposto de que a transferência de renda pelo Programa Bolsa Família não oferece êxito pelo critério da frequência escolar, uma vez que a qualidade de ensino deve ser avaliada por toda uma conjuntura educacional não se limitando somente a uma avaliação quantitativa que é através da frequência escolar, mas a uma avaliação qualitativa.

Compreende-se com esta informação que o Governo Federal ampliou a área de beneficiários levando em consideração outros dispositivos de avaliação e não só a condicionalidade de frequência de escola por parte dos filhos e a vacinação.

\section{Acauã/PI}

\section{Parte I}

O município de Acauã no estado do Piauí está localizado na região Alto Médio Canindé e foi emancipado do município de Paulistana-PI e instalado em 1997. A cidade possui 6.749 habitantes e tem sua economia baseada na agricultura e agropecuária. É um município com características rurais. O município apresenta uma evolução no IDH, ao realizar um comparativo entre os anos de 2000 e 2010, observa-se uma variação positiva de 0,274 para 0,528.

Quando realiza um comparativo entre as famílias beneficiarias no município pesquisado, onde os objetivos do PBF estão sendo concretizados, (frequência escolar mínima de $85 \%$ para crianças e adolescentes de 6 a 15 anos e de no mínimo 75\% para adolescentes de 15 e 16 anos, atualização do cartão de vacina para crianças de 0 a 6 anos e acompanhamento de saúde para as gestantes e nutrizes), observa-se que a educação tem evoluído de maneira positiva, pois de acordo com dados do IDEB os resultados são satisfatórios. 
Quadro 1 - IDEB - Resultados e Metas

\begin{tabular}{|c|c|c|l|c|c|}
\hline \multicolumn{3}{|c|}{$4^{\text {a }}$ série/5 ${ }^{\circ}$ ano } & \multicolumn{3}{c|}{ 8 $^{\text {a }}$ série/9 ${ }^{\circ}$ ano } \\
\hline Período & Metas Projetadas & IDEB observados & Período & Metas Projetadas & IDEB observados \\
\hline 2011 & 4,1 & 4,9 & 2011 & 3,5 & 3,8 \\
\hline 2013 & 4,3 & 5,1 & 2013 & 3,9 & 4,8 \\
\hline
\end{tabular}

Fonte: IDEB - Índice de Desenvolvimento da Educação Básica, disponível em http://ideb.inep.gov.br/resultado/

\section{Parte II}

O PBF no município teve início em 2004, no Governo LULA. Segundo dados do IBGE, o município apresenta 2.482 pessoas recebem algum benefício social. Ainda de acordo com o IBGE, 1.394 pessoas são beneficiadas pelo PBF, perfazendo o percentual de 20,23\% da população.

Ainda segundo dados do IBGE, a proporção de pessoas ocupadas em relação à população total são $4.7 \%$. Considerando domicílios com rendimentos mensais de até meio salário mínimo por pessoa, tinha $58.7 \%$ da população nessas condições, nessa perspectiva a maioria da população está inapta a receber o benefício.

No município em questão, segundo dados da Secretaria Municipal de Assistência Social a cidade apresenta evolução dos números de beneficiários, cerca de $15 \%$, quando se compara do ano de sua implantação aos dias atuais.

Segundo a Secretaria Municipal de Assistência Social, o PBF apresenta uma imensa aceitação no município, onde o programa é o principal instrumento de combate às desigualdades sociais.

A desigualdade social é contextualizada como diferenças econômicas que existem em diversos grupos de indivíduos no meio social. Nessa perspectiva, essas desigualdades ocasionam problemas para a sociedade, onde as diferenças de rendas são alarmantes originando as disparidades econômicas.

Segundo Camargo (1991), a desigualdade social é um guarda-chuva que compreende diversos tipos de desigualdades, desde desigualdade de oportunidade, resultado, etc., até desigualdade de escolaridade, de renda, de gênero, etc. De modo geral, a desigualdade econômica - a mais conhecida - é chamada imprecisamente de desigualdade social, dada pela distribuição desigual de renda. No Brasil, a desigualdade social tem sido um cartão de visita 
para o mundo, pois é um dos países mais desiguais. Segundo dados da ONU, em 2005 o Brasil era a $8^{\circ}$ nação mais desigual do mundo. O índice Gini, que mede a desigualdade de renda, divulgou em 2009 que a do Brasil caiu de 0,58 para 0,52 (quanto mais próximo de 1, maior a desigualdade).

\section{Metodologia}

De acordo com apresentado entende-se que o Programa Bolsa Família é um programa de transferência de renda com condicionalidades para as famílias pobres e extremamente pobres, onde as famílias que recebem os benefícios passam a ter compromisso diante do Programa. Nessa premissa, as condicionalidades representam o componente fundamental da segunda dimensão do referido Programa: a contribuição para a redução da pobreza na próxima geração ao ofertar melhores condições na entrada do mercado de trabalho.

O trabalho tem por objetivo geral analisar os impactos do PBF na trajetória escolar de famílias beneficiárias do programa no município de Acauã/PI, como objetivos específicos descrever as mudanças no acesso à educação nas vidas das famílias beneficiadas; verificar as condições de vida e de empregabilidade dos alunos beneficiários da primeira geração do PBF.

Foi utilizada pesquisa bibliográfica, obtidos através de revistas, livros, jornais, sites, entre outros. Além disso, foi realizada uma pesquisa de campo, em que se aplicou um questionário com perguntas padronizadas abertas.

A seleção das famílias para a pesquisa de campo, ocorreu por meio de um levantamento, identificando quais famílias foram as primeiras beneficiárias do PBF. A pesquisa de campo, buscou-se analisar a execução do Programa Bolsa Família no âmbito local, com a intenção de observar o cumprimento das condicionalidades para a melhoria de vida das pessoas do município de Acauã-PI.

A apresentação dos resultados será feita com base no modelo de árvore genealógica contemplando a geração beneficiária do programa e a composição do grau educacional e ocupação de forma a compreender a posição dos irmãos, pais e avós maternos e paternos. 


\section{Apresentação de Dados e Análise dos Resultados}

A pesquisa foi realizada em três famílias distintas, apresentando 53 pessoas, onde esses indivíduos, 29 são beneficiários do PBF. A família 1 é composta por 23 pessoas, sendo que a família possui 15 pessoas beneficiárias do PBF.

A família tem sua matriarca Maria, sendo essa mãe de Gabriel, Pedro, Antônio, Gilberto e José. Maria tem 12 netos: Bruno e Gabriela são filhos de Gabriel. Junior e Henrique que são filhos de Pedro, Vitória. Carlos e Ezequiel, sendo filhos de Antônio. Sebastião filho de Gilberto e Paula, Carla, Cristiane e Jean, sendo esses filhos de José. Ainda é importante destacar que Maria apresenta 5 bisnetos: Yago filho de Bruno, Bruna e Vitor filhos de Ezequiel e Evelin e Ângela filhas de Paula.

A família 2 é composta por 15 pessoas, onde o PBF beneficia 3 indivíduos da família. Josefa matriarca da família é mãe de Rosimar, Luzia e Maria. Josefa tem 9 netos: Beatriz e Luzia filhas de Rosimar, Vitória, Roberto e Charles filhos de Luzia e Débora, Bruna, Andreia e Daniela filhas de Maria. Vale ressaltar que Josefa tem 2 Bisnetos: César filho de Vitória e Marcos filho de Débora.

A família 3 é composta por 15 pessoas, apresentando 11 beneficiários do PBF. Socorro é a matriarca da família, sendo a mãe de Luzia, Juliana, Tiago e Felipe. Socorro tem 9 netos: Érica, Emerson e Lucas filhos de Luzia, Roseane e Ricardo filhos de Juliana, Junior filho de Ricardo e Erick, Helena e Gabriela filhos de Felipe. Socorro tem apenas 1 bisneto: Diego filho de Emerson.

Com base nos dados encontrados na pesquisa de campo, observa-se o grau de instrução e ocupação das famílias.

Quadro 2 - Dados da Família 1

\begin{tabular}{|c|c|c|}
\hline Matriarca & \multicolumn{1}{|c|}{ Grau de Instrução } & Ocupação \\
\hline Maria & Analfabeta & Dona de casa \\
\hline Filhos de Maria & Grau de Instrução & Ocupação \\
\hline Gabriel & Ensino Fundamental II & Pedreiro \\
\hline Pedro & Ensino Fundamental I & Trabalhador rural \\
\hline Antônio & Ensino médio completo & Auxiliar de serviços gerais \\
\hline
\end{tabular}




\begin{tabular}{|c|c|c|}
\hline Gilberto & Ensino médio incompleto & Trabalhador rural \\
\cline { 3 - 3 } José & $1^{\mathrm{a}}$ série ensino fundamental & Trabalhador rural \\
\hline Netos de Maria & Grau de Instrução & Ocupação \\
\hline Bruno & $\begin{array}{c}\text { Ensino Superior } \\
\text { Incompleto }\end{array}$ & Atendente em lojas \\
\hline Gabriela & $3^{\circ}$ ano Ensino médio & Estudante \\
\hline Junior & $2^{\circ}$ ano ensino médio & Estudante \\
\hline Henrique & $1^{\circ}$ ano Ensino médio & Estudante \\
\hline Vitória & Ensino Superior & Estudante \\
\hline Carlos & $1^{\circ}$ ano Ensino médio & Estudante \\
\hline Ezequiel & Ensino fundamental II & Trabalhador rural \\
\hline Sebastião & $1^{\circ}$ ano Ensino médio & Estudante \\
\hline Paula & Ensino médio completo & Dona de casa \\
\hline Carla & $3^{\circ}$ ano Ensino médio & Estudante \\
\hline Cristiane & $2^{\circ}$ ano Ensino médio & Estudante \\
\hline Jean & $5^{\circ}$ ano ensino fundamental & Estudante \\
\hline
\end{tabular}

Quadro 3 - Dados da Família 2

\begin{tabular}{|c|c|c|}
\hline \multicolumn{2}{|c|}{ Matriarca } & \multicolumn{2}{c|}{ Grau de Instrução } & Ocupação \\
\hline Josefa & Ensino Fundamental I & Dona de casa \\
\hline Filhos de Josefa & Grau de Instrução & Ocupação \\
\hline Rosimar & $\begin{array}{c}8^{\text {a }} \text { série do ensino } \\
\text { fundamental }\end{array}$ & Dona de casa \\
\hline Luzia & Ensino Superior & Professora pedagoga \\
\hline Maria & Ensino médio completo & Dona de loja \\
\hline Netos de Josefa & Grau de Instrução & Ocupação \\
\hline Beatriz & $6^{\circ}$ ano ensino fundamental & Estudante \\
\hline Luísa & $7^{\circ}$ ano Ensino fundamental & Estudante \\
\hline Vitória & Ensino médio completo & Estudante \\
\hline Roberto & $1^{\circ}$ ano Ensino médio & Estudante \\
\hline Charles & $2^{\circ}$ ano ensino médio & Estudante \\
\hline Debora & $2^{\circ}$ ano ensino médio & Estudante \\
\hline Bruno & $9^{\circ}$ ano Ensino fundamental & Estudante \\
\hline Andreia & $2^{\circ}$ ano ensino médio & Estudante \\
\hline Daniela & $7^{\circ}$ ano ensino fundamental & Estudante \\
\hline
\end{tabular}


Quadro 4 - Dados da Família 3

\begin{tabular}{|c|c|c|}
\hline \multicolumn{1}{|c|}{ Matriarca } & \multicolumn{1}{c|}{ Grau de Instrução } & Ocupação \\
\hline Socorro & Analfabeta & Dona de casa \\
\hline Filhos de Socorro & Grau de Instrução & Ocupação \\
\hline Luzia & $\begin{array}{c}7^{\text {a }} \text { série do ensino } \\
\text { fundamental }\end{array}$ & Dona de casa \\
\hline Juliana & Ensino médio completo & Vendedora \\
\hline Tiago & $\begin{array}{c}8^{\text {a }} \text { série do ensino } \\
\text { fundamental }\end{array}$ & Trabalhador Rural \\
\hline Felipe & Ensino médio completo & Trabalhador Rural \\
\hline Netos de Socorro & Grau de Instrução & Ocupação \\
\hline Erica & $6^{\circ}$ ano ensino fundamental & Estudante \\
\hline Emerson & Ensino Superior & Professor de matemática \\
\hline Lucas & $1^{\circ}$ ano ensino médio & Estudante \\
\hline Roseane & $2^{\circ}$ ano ensino médio & Estudante \\
\hline Ricardo & $1^{\circ}$ ano Ensino médio & Estudante \\
\hline Junior & $8^{\circ}$ Ensino fundamental & Estudante \\
\hline Erick & $2^{\circ}$ ano ensino médio & Estudante \\
\hline Helena & $1^{\circ}$ ano Ensino médio & Estudante \\
\hline Gabriela & $9^{\circ}$ ano ensino fundamental & Estudante \\
\hline
\end{tabular}

De acordo com os dados, observa-se que a primeira geração das famílias quase todos eram analfabetos, sua ocupação era apenas cuidar da casa. Percebe-se que essa primeira geração, no caso os avós apresentam suas profissões de acordo com seu grau de instrução, suas profissões eram apenas voltadas para o meio rural.

Ainda de acordo com os dados, a segunda geração das famílias apresenta uma melhora no seu grau de instrução, porém de maneira insignificante para a inserção no mercado de trabalho, é visto que a maioria dos indivíduos seguiram a profissão seguidas pelos seus descendentes, voltadas para o meio rural.

A terceira geração da família, observa-se que os indivíduos possuem um grau de instrução mais elevados que os seus pais, com uma ocupação diferente dos seus descendentes. Nessa premissa o PBF estimula a qualificação das pessoas, pois estes para ser beneficiado pelo programa, necessita da participação nas instituições de ensino. 
Com base nas análises as condicionalidades do PBF, tem como premissa que as crianças assistenciadas cumpram adequadamente o ciclo da educação básica. Portanto, uma situação melhor do que a vivenciada por seus pais e familiares.

Entende-se que essas crianças, quando se tornarem adultas, apresentaram melhores condições de inserção no mercado de trabalho e desenvolvimento do exercício de cidadania, em um âmbito geral com a melhora do nível educacional dos beneficiários, isso propicia a ruptura do ciclo intergeracional da pobreza enfatizado pelo $\mathrm{PBF}$.

Com base nos dados, o Programa Bolsa Família com adequado monitoramento das condicionalidades permite a identificação de vulnerabilidades que afetam ou impedem o acesso das famílias beneficiárias aos serviços a que têm direito, demandando ações do Poder Público, voltadas a seu acompanhamento.

O principal ponto que tem como proposta o PBF é o rompimento dos ciclos de pobreza que marcam as gerações, tendo como premissa o direito à educação como elemento fundamental da inclusão social das famílias, sendo a educação escolar o principal meio que irá combater essas desigualdades sociais.

Segundo Ana Fonseca (FONSECA, 2001) e Eduardo Suplicy (SUPLICY, 2004) o formato de utilizar programas de transferência de renda com forma de romper a chamada transmissão intergeracional da pobreza veio surgir no Brasil a partir das contribuições do economista José Márcio de Camargo às propostas iniciais dos Programas de Garantia de Renda Mínima, encabeçadas por algumas prefeituras municipais nos anos noventa do século XX.

De acordo com Camargo (CAMARGO, 1991), pelo fato das situações de carências socioeconômicas de grande parte da população, as crianças são estimuladas a trabalhar em idade precoce para contribuir com a renda familiar. Fato esse que cria um círculo vicioso já que essas crianças, ao ingressarem cedo no mercado de trabalho, diminuiriam a sua escolaridade e reduziriam drasticamente suas chances de sair da pobreza quando na idade adulta. Portanto, como forma de romper este ciclo de transmissão intergeracional, o Estado buscou garantir uma renda familiar compatível com a renda gerada pelo trabalho infantil, de maneira a possibilitar o aumento da escolaridade das crianças e também aumentar suas chances de saírem da pobreza quando adulta.

$\mathrm{O}$ cumprimento das metas estabelecidas no PBF, tem uma expectativa que essas crianças, ao se tornarem adultas, terão melhores condições de inserção no mercado de trabalho 
e desenvolvimento do exercício de cidadania, e esse é o sentido esperado de ruptura do ciclo intergeracional da pobreza no âmbito do Programa Bolsa Família.

$\mathrm{O}$ aumento da frequência escolar buscado pelo PBF, provoca um aumento da escolaridade e consequentemente a possibilidade de profissionalização de crianças e adolescentes na idade adulta.

Entretanto, a cidade pesquisada apresenta um perfil rural, ocorrendo uma baixa na oferta de serviços qualificados. Na sua ausência, os beneficiários tenderão a seguir o mesmo caminho dos pais. Neste sentido o PBF se torna eficaz apenas por incentivar a participação escolar, porém a tendência é que o ciclo da pobreza continue existindo.

Para romper o ciclo intergeracional da pobreza é necessário que o município apresente programas que garantem uma geração de empregos, pois isso aliado ao PBF, possibilita os jovens inserir no mercado de trabalho e, melhora na qualidade de vida.

\section{Conclusão}

O objetivo principal desse estudo era de analisar a aplicabilidade do Programa Bolsa Família, caracterizando o seu desenvolvimento frente a demanda atendidos pelo programa.

Conforme se pode observar, os cumprimentos das condicionalidades não estariam sendo satisfatoriamente fiscalizado pelo governo. Segundo dados do Ministério da Saúde, em 2006 não foram monitorados, por falta de dados, a condicionalidade exigida em relação a $68 \%$ das famílias beneficiadas, tais falhas fizeram com que, por exemplo, os índices de vacinação e de nutrição entre famílias beneficiadas e não beneficiadas fossem equivalentes, essas falhas apontadas já vem sendo corrigidas nos meses de junho e julho de 2007, o Ministério da Educação recebeu $78,9 \%$ das informações relativas a participação escolar das crianças e adolescentes cadastrados no Programa, o que representou uma melhoria de 10 pontos percentuais em relação a maio e abril do mesmo ano, com isso, dos mais 15 milhões de alunos atendidos, 11 milhões tiveram a participação escolar computada.

Nesse sentido, o Programa Bolsa Família trouxe melhorias para as famílias uma vez que as crianças deixam de trabalhar para somente estudar. Entende-se que o ciclo intergeracional não é rompido somente com a transferência monetária associada ao cumprimento das condicionalidades. 
Desde a criação e implementação do Programa Bolsa Família criados no município, foram ampliados os acessos dos beneficiários aos serviços prestados a sociedade, entre eles destaca a educação, onde busca principalmente o aumento das taxas de matricula, além do aumento da frequência das crianças e adolescentes pobres às escolas, conforme proposta do PBF.

A realização das condicionalidades do PBF deve resultar, para as famílias valorização da educação, sendo que essas condições ampliam capital social, promovendo a elevação da escolaridade criando importante mudança na concepção de direito das famílias e o acesso ao mercado de trabalho.

Conclui-se que o PBF é um importante instrumento de combate às desigualdades sociais. A educação é a ferramenta principal para o combate às desigualdades, a união das condicionalidades do PBF com a educação se mostra eficaz, porém não suficiente para o combate da reprodução intergeracional da pobreza.

\section{Referências}

BARROS, Ricardo; HENRIQUES, Ricardo; e MENDONÇA, Rosane. Revista Brasileira de Ciências Sociais. In: Desigualdade e pobreza no Brasil: retrato de uma estabilidade inaceitável. Vol.15. №. 42, 2000 .

BRASIL. Ministério do Desenvolvimento Social. Benefícios e condicionalidades - Programa Bolsa Família. 2008. Disponível em: <http://www.mds.gov.br/BolsaFamilia> Acesso em 09 nov.2011.

. Portaria do Ministério do Desenvolvimento Social e Combate à Fome nº 246 de 20 de maio de 2005 , solicita a indicação de um comitê de controle social formado por representantes da sociedade civil e de setores da prefeitura.

BARROS, R. et al. Uma análise das principais causas da quebra recente na desigualdade de renda brasileira. $\mathrm{N}^{\mathrm{o}}$ 1203. IPEA, Rio de Janeiro, 2002.

BEHRING, E.R; BOSCHETTI, I. Política Social: fundamentos e história. 8.ed. São Paulo: Cortez, 2011.

Cardoso, E. e A. P. Souza. The impact of cash transfers on child labor and school attendance in Brazil. São Paulo: Departamento de Economia da Universidade de São Paulo 2003.

CAMARGO, J. M. Pobreza e garantia de renda mínima. Folha de São Paulo, São Paulo, dez. 1991. 
CAMARGO, Orson. "Desigualdade social"; Brasil Escola. Disponível em <https://brasilescola.uol.com.br/sociologia/classes-sociais.htm>. Acesso em 04 de junho de 2018.

CUNHA, Rosani. Transferência de renda com condicionalidade: a experiência do Programa Bolsa Família. In Concepção e gestão da proteção social não contributiva no Brasil. Brasília, MDS, UNESCO, 2009.

DEMO, Pedro. Educação e qualidade. 11 ed. São Paulo. Papirus Ltda, 1995. P.S. 160.

DINIZ, Simone. Critérios de justiça e programas de renda mínima. Katál, Florianópolis, v.10, n.1, p.105-114, jan/jun 2007.

DAVOK, DelsiFries. Qualidade em educação. São Paulo. v.12, n.3, p.505-513. set.2009. Disponível em: 〈http://www.scielo.br/ped/aval/v12n3/a07v12n3.pdf> Acesso em: 09 nov.2011.

FALEIROS, Vicente de Paula. Estratégias em Serviço Social. São Paulo, Cortez, 1997.

FONSECA, A.M.M. Família e Politica de Renda Mínima. São Paulo: Cortez, 2003.

GIL, A.C. Como elaborar projetos de pesquisa. 4 ed. São Paulo: Atas, 2010 p. 175.

IAMAMOTO, Marilda Villela. O Serviço Social na contemporaneidade. São Paulo: Cortez, 1992.

Projeto Profissional, Espaços Ocupacionais e Trabalho do Assistente Social na Atualidade. Atribuições Privativas do (a) Assistente Social Em questão. Brasília: CFESS,2002.

IAMAMOTO, M.V; CARVALHO, R. Relações sociais e serviço social no Brasil: esboço de uma interpretação histórico-metodológica. 18.ed. São Paulo: Cortez, 2005.

KILL, Mariana. Educação e Pobreza: análise das condicionalidades do Programa Bolsa Família no Centro de Ensino Médio Elefante Branco - Brasília/DF 2014. 63 p.

MEDEIROS, Marcelo; BRITO, Tatiane; SOARES, Fábio. Transferência de renda no Brasil: novos estudos. São Paulo, v.79, p.5-21, nov.2007.

MOTA, A. E. A nova fábrica de consensos: ensaios sobre a reestruturação empresarial, o trabalho e as demandas ao serviço social. São Paulo: Cortez, 1998.

NETTO, José Paulo. Capitalismo Monopolista e Serviço Social. 2a ed., São Paulo: Cortez, 1992.

OLIVEIRA, Luis Felipe Batista; SOARES, Sergei, S.D. O Impacto do Programa Bolsa

Família sobre a repetência: Resultados a partir do cadastro único, projeto, frequência e censo escolar. Ipea Rio de Janeiro, fevereiro de 2013. Texto para discussão / Instituto de Pesquisa Econômica Aplicada. Brasília : Rio de Janeiro : Ipea, 1990. 28 p.

PEREIRA, P. A.P. Politica Social: temas e questões 2.ed. São Paulo: Cortez, 2009.

RICHARDSON, R. J. Pesquisa social: métodos e técnicas. 3.ed. São Paulo: Atlas, 1999.

SANTOS, Judit Camila. Solidariedade: uma luta contra a fome. Monografia de Graduação em Ciências Sociais. Depto. de Ciências Sociais. UFPR: Curitiba, 2004. 
SANTOS L. Distribuição de competência no Sistema Único de Saúde: o papel do Estado nas três esferas de governo no SUS. Brasília: OPS/OMS; 1994.

SCHWARTZMAN, Simon. As causas da pobreza. Rio de Janeiro: editora FGV, 2004. 208 p.

SILVA, Maria Ozanira da Silva e. Formação Profissional do Assistente Social: inserção na realidade social e na dinâmica da profissão. 2. ed. São Paulo: Cortez, 1995.

SILVA e SILVA, M. O. (Coord.). O Serviço Social e o Popular: resgate teórico-metodológico do projeto profissional de ruptura. São Paulo: Cortez, 1995.

SILVA; SILVA, M. O; YAZBEK, M. C; GIOVANNI, G. A Politica Social Brasileira no século XXI: a prevalência dos programas de transferência de renda. 4.ed.rev. atual. São Paulo: Cortez, 2008.

SOARES, Sergei; SÁTYRO, Natália. O Programa Bolsa Família: desenho institucional, impactos e possibilidades futuras. Texto para Discussão, Instituto de Pesquisa Econômica Aplicada (IPEA), 2009.

SOUZA, Renilson Rehem de. O sistema público de saúde brasileiro. Brasília: Ministério da Saúde, 2002. Disponível em <http://www.opas.org.br/servico/arquivos/Destaque828.pdf >. Acesso em $16 / 11 / 2013$.

STEIN, Rosa Helena. Mudanças recentes nas políticas sociais: O lugar das rendas mínimas na reestruturação dos regimes de proteção social. In: As políticas de Transferência de Renda na Europa e na América Latina: recentes ou tardias estratégias de proteção social? Tese de doutorado apresentada ao Centro de Pesquisa e Pós-graduação sobre as Américas- CEPPAC/ICS/UnB, 2005.

SUPLICY, E. Renda de Cidadania: a saída é pela porta. São Paulo: Cortez, 2004.

Como citar este artigo (Formato ABNT):

MACEDO, Rogério Rodrigues de. Transferência de Recursos Através do Programa Bolsa Família no Município de Acauã-PI. Id on Line Rev.Mult. Psic., 2018, vol.12, n.41, p.414-434. ISSN: 1981-1179.

Recebido: 21/06/2018

Aceito 26/06/2018 